„TURYZM”, 1999, t. 9, z. 1

Wlodzimierz Kurek

\title{
ROZWÓJ TURYSTYKI I JEJ WPŁYW NA ŚRODOWISKO PRZYRODNICZE ALP
}

\author{
LE DEVELOPPEMENT DU TOURISME ET SON INFLUENCE \\ SUR LE MILIEU NATUREL DES ALPES \\ THE DEVELOPMENT OF TOURISM AND ITS INFLUENCE \\ ON THE NATURAL ENVIRONMENT OF THE ALPS
}

\begin{abstract}
W pierwszej części opracowania przedstawiono rozwój turystyki w Alpach, która jest obecnie główną funkcją tego regionu. Następnie przedmiotem analizy jest zagospodarowanie i ruch turystyczny na tym obszarze, a w szczególności turystyka narciarska. Omówiono przy tym typy ośrodków narciarskich, ich lokalizację i funkcjonowanie. Na koniec ukazano wplyw budowy infrastruktury turystycznej na środowisko przyrodnicze Alp.
\end{abstract}

\section{UWAGI WSTĘPNE}

Przez wiele wieków Alpy były wyłącznie rejonem gospodarki rolnej: hodowli bydła i owiec oraz uprawy zbóż, a później ziemniaków. Dużą część powierzchni zajmowały lasy, wykorzystywane w budownictwie i na opał. Lasy rosnace na stromych stokach stanowiły barierę chroniącą przed lawinami.

Tradycyjne, mało wydajne rolnictwo nie dawało możliwości utrzymania szybko rosnącej liczby ludności. Toteż zapotrzebowanie na tanią siłę robocza, powstałe w wyniku rewolucji przemysłowej, spowodowało masowy odpływ ludności, który w niektórych częściach Alp doprowadził prawie do wyludnienia się gór. Dopiero rozwój turystyki, zwłaszcza po II wojnie światowej, spowodował ożywienie gospodarcze wielu regionów alpejskich. Równocześnie jednak intensywny rozwój turystyki stał się czynnikiem degradacji środowiska. Najbardziej dynamicznie rozwijającą się formą turystyki było narciarstwo. Umożliwienie korzystania $\mathrm{z}$ walorów śniegowych wymaga jednakże budowy licznych 
urządzeń technicznych i całej infrastruktury noclegowo-usługowej. Skutkiem tego większa część obszaru Alp jest obecnie gęsto pocięta wyciągami i trasami narciarskimi, a na wysokich grzbietach $\mathrm{i}$ stokach wznoszą się zabudowania ośrodków narciarskich. Ich budowa spowodowała nieodwracalne przekształcenia środowiska przyrodniczego i krajobrazu alpejskiego.

\section{HISTORIA TURYSTYKI W ALPACH}

Już w średniowieczu istniały w Alpach pewne formy turystyki, jak pielgrzymki do miejsc uważanych za święte i przyjazdy do wód leczniczych. Dopiero jednak w XIX w. zaczął się rozwijać nowoczesny ruch turystyczny. Rozwój turystyki alpejskiej, był regionalnie zróżnicowany. Można jednakże wyodrębnić dla całego obszaru Alp sześć faz jej rozwoju (B ä t z i n g 1991): 1) czas odkryć (1780-1880), 2) belle-epoque (1880-1914), 3) okres międzywojenny (1914 -1950), 4) okres masowej turystyki letniej (1955-1975), 5) okres masowej turystyki zimowej (1965-1981), 6) najmłodsza faza (od 1982).

W trwającym sto lat okresie „odkrywania” Alp odwiedziło ten region niewielu turystów. Spędzenie urlopu w Alpach było raczej przygodą aniżeli wypoczynkiem. Był to początek rozwoju alpinizmu, którego prekursorami stali się Anglicy. Interesowali się oni nie zdobytymi szczytami i nie przetartymi szlakami. Infrastruktura turystyczna, poza nielicznymi, tradycyjnymi kurortami była skromna i koncentrowała się w takich miejscowościach, jak Chamonix, Zermatt, czy Grindelwald (B ä t z i n g 1991).

Najważniejszymi osiagnnięciami belle-epoque był rozwój komunikacji kolejowej na obszarze Alp i kolejek górskich prowadzących do punktów widokowych. W Szwajcarii została zbudowana kolej zębata na przełęcz Jungfrau (ok. 3,5 tys. m n.p.m.). Te urządzenia przez 60 lat okazały się najlepszymi rozwiązaniami technicznymi w wysokich górach. Dopiero w latach siedemdziesiątych zbudowano inne kolejki linowe prowadzące na najwyższe szczyty alpejskie. W tym okresie z wypoczynku letniego w Alpach korzystały jedynie elity społeczne. Dla nich wzniesiono wiele hoteli. Około $2 / 3$ ogólnego ruchu turystycznego na obszarze Alp skupiało się wtedy w Alpach szwajcarskich (Berner, Oberland, Wallis, Graubünden). W Austrii do rozkwitu doszły regiony Semmering, Salzkammergut i Kärntner Seen. Ponadto na obszarach wysoko położonych, dzięki inicjatywom towarzystw alpejskich, rozwijała się turystyka wysokogórska (B ä t z ing 1991, K u r e h a 1995).

Po I wojnie światowej rozpoczął się okres rozwoju turystyki zimowej. Ponadto region turystyczny rozszerzył się od swojego pierwotnego centrum w Szwajcarii na sąsiednie obszary. W Austrii punkt ciężkości znajdował się we wschodniej części kraju i dominowali tu turyści krajowi. 
Okres letniej turystyki masowej w Alpach rozpoczą się od ok. 1955 r. dzięki wzrostowi dobrobytu w krajach zachodniej Europy oraz rozwojowi indywidualnej motoryzacji. Dzięki temu szersze grupy społeczne mogły spędzać urlopy w alpejskich miejscowościach turystycznych. Powstawały wtedy różnorodne rodzaje bazy noclegowej. Podstawą były pokoje prywatne, pensjonaty i małe hotele. Budowano też wtedy liczne kolejki linowe prowadzące na szczyty alpejskie. Cechą charakterystyczną rozwoju turystyki w tym okresie było jej rozprzestrzenienie się na obszarze obejmującym połowę ogólnej powierzchni Alp (B ät z ing 1991).

Lata 1965-1981 były okresem intensywnego rozwoju turystyki zimowej. Wiele miejscowości, wykorzystywanych dotychczas tylko w sezonie letnim, dzięki rozwojowi sportów zimowych zmieniono w ośrodki dwusezonowe. W znacznej jednak części turystyka zimowa koncentrowała się w dużych, monofunkcyjnych stacjach sportów zimowych, zlokalizowanych powyżej stałych osiedli ludzkich. Takie ośrodki do dzisiaj znajdują się zwłaszcza w Alpach francuskich i włoskich. Zapewniają one korzystanie $\mathrm{z}$ długiego sezonu zimowego (niektóre zlokalizowane na lodowcach funkcjonują przez cały rok), są nowoczesne i odznaczają się większą efektywnością ekonomiczną od ośrodków tradycyjnych.

Ostatni okres w rozwoju turystyki alpejskiej charakteryzuje się bardzo silnym wzrostem świadomości ekologicznej społeczeństw krajów zachodnioeuropejskich i rozwojem alternatywnych form turystyki, w tym turystyki ekologicznej. Nie ma to jednak większego wpływu na rozmiary ruchu turystycznego w istniejących ośrodkach sportów zimowych.

Scharakteryzowane powyżej okresy rozwoju turystyki w Alpach dotyczą zwłaszcza obszarów niemieckojęzycznych: Szwajcarii, zachodniej Austrii, Bawarii i południowego Tyrolu. Na pozostałych obszarach Alp widoczne są w procesie rozwoju turystyki różnice regionalne.

\section{ZAGOSPODAROWANIE I RUCH TURYSTYCZNY}

Ruch turystyczny w Alpach szacuje się na $100 \mathrm{mln}$ turystów rocznie, z czego ok. $40 \%$ stanowia przyjazdy urlopowe i $60 \%$ weekendowe (Europe's Enwironment... 1995). Znamienne jest, że od ponad 20 lat nie zmienia się liczba turystów w sezonie letnim, natomiast zwiększa się szybko liczba turystów w okresie zimowym.

Ocenia się, że w 1990 r. ok. 50 mln turystów przebywało w Alpach w celu uprawiania narciarstwa. Działa tutaj ok. 600 ośrodków sportów zimowych i ok. 14 tys. wyciagów (Europe's Enwironment... 1995).

Są różne typy ośrodków narciarskich. Jedne to ośrodki małe lub średnie zlokalizowane w obrębie dawnych wsi, inne to wielkie stacje zbudowane na terenach nie zamieszkałych (Alpe d'Huez, Verbier, Kitzbühel) oraz rozbudowa- 
ne dawne ośrodki turystyki letniej (Chamonix, Zermatt, St. Moritz, Cortina d'Ampezzo). W Alpach francuskich, gdzie zdecydowanie dominuje turystyka zimowa, znajdują się trzy generacje stacji sportów zimowych. Stacje I generacji, np. Val d'Isére, Alpe d'Huez powstały w okresie międzywojennym; stacje II generacji, np. Courchevel, Les Duex Alpes powstały pomiędzy 1948-1962 r. oraz stacje III generacji, tzw. zintegrowane, budowane po 1960 r. np. La Plagne, Tignes, Isola (Barbier 1984). Stacje III generacji zajmują tereny powyżej górnej granicy osadnictwa wiejskiego i dysponują najczęściej 10-15 tys. miejsc oraz dziesiątkami wyciagów. Zbudowane zostały przez kapitał pochodzący spoza regionu. W Austrii i w Szwajcarii liczne są natomiast mniejsze ośrodki turystyczne, powstałe w wyniku rozbudowy dawnych wsi. Ich współwłaścicielami są rodziny góralskie. Niektóre ośrodki przekształciły się w duże, wielofunkcyjne miasta (Lugano, Interlaken, Füssen, Villach) (B a r b i e r. 1984).

Średnia wysokość stacji narciarskich w Szwajcarii

La hauteur moyenne des stations de ski en Suisee

\begin{tabular}{|l|c|c|}
\hline \multicolumn{1}{|c|}{ Region } & Liczba obszarów narciarskich & Średnie wzniesienie m n.p.m. \\
\hline Jura & 15 & 1400 \\
Alpy FD+FR a & 19 & 1866 \\
Wallis & 54 & 2534 \\
Berno (bez Jury) & 35 & 1930 \\
Szwajcaria środkowa & 35 & 1783 \\
Tessin & 8 & 1910 \\
Szwajcaria wschodnia & 18 & 1646 \\
Gryzonia & 46 & 2515 \\
\hline Szwajcaria-ogółem & 230 & 2104 \\
\hline
\end{tabular}

${ }^{\mathrm{a} A l p y ~ V a u d y j s k i e ~ i ~ F r y b u r s k i e . ~}$

Źródło: B. A b e g g, H. E I s a s s e r 1996.

Aby wydłużyć sezon zimowy, trasy zjazdowe znajdują się często na dużych wysokościach, powyżej górnej granicy lasów, a nawet na lodowcach, np. w Alpach francuskich w Chamonix osiagają 3840 m n.p.m., w Duex-Alpes - 3570 m, w Alpach $3460 \mathrm{~m}$. Często stacje w jednym masywie łączą swe wyciągi i trasy w duże systemy, znajdujące się nawet w granicach sąsiednich państw (np. Châtel w Szwajcarii i Morzine-Avoriaz we Francji, czy francusko-włoskie Mongenevre i Voie-Lactée, Val Fréjus i Bardonneche.

Model francuski stacji zimowych oceniany jest z punktu widzenia ekologicznego, społecznego i tradycji kulturowych negatywnie. Stacje francuskie sa przede wszystkim duże, leżą na stokach i grzbietach wysoko wzniesionych nad 
poziom morza i nie wpływają aktywizująco na region, przynosząc jedynie korzyści inwestorom z zewnątrz. Natomiast ośrodki austriackie są uważane za bardziej przyjazne środowisku, a poza tym ludność miejscowa ma decydujący wpływ na ich planowanie, inwestowanie oraz zarządzanie.

Turystyka w sezonie letnim jest mniej skoncentrowana i nie wymaga budowy tylu urządzeń, jak w wypadku turystyki zimowej. Główną formą turystyki letniej jest turystyka piesza oraz wypoczynek nad jeziorami alpejskimi.

Obszary narciarskie na lodowcach w Austrii

Les terrains de ski sur les glaciers en Autriche

\begin{tabular}{|l|c|c|c|}
\hline Nazwa obszaru & Rok otwarcia & $\begin{array}{c}\text { Powierzchnia w ha } \\
\text { (stan na 1985) }\end{array}$ & $\begin{array}{c}\text { Najwyższy punkt } \\
\text { (m n.p.m.) }\end{array}$ \\
\hline Kitzsteinhorn & 1996 & 181 & 3029 \\
Dachstein & 1969 & 81 & 2700 \\
Zillertal & 1969 & 459 & 3286 \\
Stubaital & 1973 & 591 & 3200 \\
Ötztal & 1975 & 325 & 3260 \\
Kaunertal & 1980 & 313 & 3160 \\
Pitztal & 1983 & 468 & 3440 \\
Mölltal & 1987 & - & 3160 \\
\hline
\end{tabular}

T a b e l a III

Gminy o największej liczbie przewozów kolejkami liniowymi w Austrii w 1990 r.

Les communes autrichiennes dont les téléfériques ont transporté le plus de passagers en 1990

\begin{tabular}{|l|c|l|c|}
\hline \multicolumn{1}{|c|}{ Gmina } & Przewozy $(\mathrm{mln})$ & \multicolumn{1}{|c|}{ Gmina } & Przewozy (mln) \\
\hline Sölden & 30,1 & Bad Kleinkirchheim & 8,7 \\
Saalbach-Hinterglemm & 22,8 & Neustift im Stubaital & 8,3 \\
Lech & 15,3 & Hermagor-Pressegger See & 7,6 \\
St. Anton am Arlberg & 14,4 & Rohrmoos-Untertal & 7,5 \\
Ischgl & 13,8 & Kirchberg in Tirol & 7,3 \\
Tux & 12,0 & Badgastein & 7,3 \\
St. Gallenkirch & 11,1 & Jochberg & 7,0 \\
Flachau & 9,1 & Kitzbühel & 6,7 \\
Zell am Zee & 9,0 & Wagrain & 6,6 \\
Kaprum & 8,9 & St. Johann im Pongau & 6,6 \\
\hline
\end{tabular}

Źr ódło: M. Ku r e ha 1995. 
Turystyka narciarska wywiera bardzo silny, negatywny wpływ na środowisko przyrodnicze Alp. Budowa tras narciarskich i różnorodnej infrastruktury, włączając w to drogi i parkingi, spowodowała zniszczenie dużych obszarów lasów, zmieniła znacząco krajobraz, zwiększyła częstość występowania lawin. Budowa stacji sportów zimowych wymaga często przekształcenia dużej powierzchni stoków górskich, używa się do tego materiałów wybuchowych i potężnych maszyn. Na przykład, w czasie budowy obiektów noclegowych i tras narciarskich w Albertville przemieszczono łącznie ok. $1 \mathrm{mln} \mathrm{m}^{3}$ ziemi. Teren taki zagrożony jest później przez osuwiska i lawiny.

T a b e l a IV

Polożenie terenów narciarskich w stosunku do form użytkowania ziemi w Tyrolu

La situation des terrains de ski par rapport aux formes de l'exploitation de la terre au Tyrol

\begin{tabular}{|l|r|r|r|r|r|r|}
\hline \multirow{3}{*}{ Powiat } & \multicolumn{6}{|c|}{ Powierzchnia terenów narciarskich w 1991 r. } \\
\cline { 2 - 7 } & \multicolumn{3}{|c|}{ hale } & \multicolumn{2}{c|}{ lasy } & \multicolumn{1}{c|}{ obszary osadniczo-rolnicze } \\
\cline { 2 - 7 } & ha & $\%$ & ha & $\%$ & ha & $\%$ \\
\hline Imst & 910,7 & 83,8 & 83,2 & 7,7 & 93,3 & 8,6 \\
Innsbruck & 344,6 & 43,8 & 251,9 & 32,0 & 190,2 & 24,2 \\
Kitzbühel & 925,1 & 50,7 & 400,7 & 22,0 & 498,4 & 27,3 \\
Kufstein & 418,6 & 44,3 & 204,0 & 21,6 & 322,4 & 34,1 \\
Landeck & 1328,7 & 76,4 & 246,5 & 14,2 & 163,6 & 9,4 \\
Lienz & 298,9 & 61,2 & 119,8 & 24,5 & 69,4 & 14,2 \\
Reutte & 149,8 & 24,3 & 221,1 & 36,0 & 245,5 & 39,8 \\
Schwaz & 675,8 & 62,5 & 268,4 & 24,8 & 137,1 & 12,7 \\
\hline Tyrol & 5052,2 & 59,0 & 1796,6 & 21,0 & 1719,9 & 20,1 \\
\hline
\end{tabular}

Źródło: M. K u re ha 1995.

Jak wynika $\mathrm{z}$ tab. IV, obrazującej położenie terenów narciarskich w stosunku do form użytkowania ziemi, najintensywniej wykorzystywane i najbardziej zagospodarowane są obszary hal, leżące w najwyższych partiach Alp, a ponadto, ale w mniejszym stopniu, strefy leśna i osadniczo-rolnicza. Na przykład w Tyrolu aż 59\% terenów narciarskich znajduje się w strefie hal. Te obszary są zatem najbardziej narażone na oddziaływanie turystyki, głównie narciarstwa.

Przeprowadzanie tras narciarskich i wyciagów poprzez strefę lasów wymaga wycięcia znacznej powierzchni leśnej, następstwem czego jest narażanie pobliskich drzewostanów na działanie wiatrów i rozwój populacji szkodników drzew.

Ponieważ większość turystów podróżuje samochodami, powoduje to znaczne zanieczyszczenie powietrza. Na przykład w Szwajcarii aż 70\% turystów pod- 
różuje przez Alpy samochodami. Emisję zanieczyszczeń samochodowych oraz emisję zanieczyszczeń powstałą z ogrzewania hoteli i drugich domów ukazuje na przykładzie Szwajcarii tab. V.

Jak wynika z tab. V, zanieczyszczenie powietrza jest przede wszystkim skutkiem ogromnego ruchu samochodów osobowych i dostawczych, zaś w mniejszym stopniu skutkiem ogrzewania hoteli, pensjonatów, drugich domów itd. Problem ten pogłębia fakt, że w alpejskich dolinach i kotlinach śródgórskich wymiana powietrza jest utrudniona, oraz że często inwersje temperatur sprzyjaja koncentracji zanieczyszczeń. Największe stężenie zanieczyszczeń powietrza występuje w zimie; wtedy właśnie w miejscowościach turystycznych jakość powietrza jest tak zła, jak w dużych ośrodkach miejskich i przemysłowych (B ä t zing 1991).

T a b e la $\mathrm{V}$

Udział turystyki w zanieczyszczeniu powietrza w Szwajcarii

La participation du tourisme dans la pollution de l'air en Suisse

\begin{tabular}{|l|c|c|c|}
\hline $\begin{array}{c}\text { Rodzaj } \\
\text { zanieczyszcze- } \\
\text { nia }\end{array}$ & $\begin{array}{c}\text { Ruch turys- } \\
\text { tyczny } \\
(\mathrm{t} / \mathrm{rok})\end{array}$ & $\begin{array}{c}\text { C.o. whotelach } \\
\text { i drugich domach } \\
(\mathrm{t} / \mathrm{rok})\end{array}$ & $\begin{array}{c}\text { Udział ruchu turystycznego } \\
\text { i c.o. w zanieczyszczeniu } \\
\text { ogółem w Szwajcarii }\end{array}$ \\
\hline Dwutlenek siarki & 600 & 800 & 1 \\
Tlenki azotu & 38000 & 600 & 18 \\
Węglowodory & 24000 & 500 & 7 \\
Tlenek węgla & 136000 & 7000 & 23 \\
Sadza & 50 & 100 & 1 \\
Olów & 160 & - & 24 \\
\hline
\end{tabular}

Ź r ó d ł o: Europe's Environment... 1995.

W celu ochrony powietrza i eliminacji hałasu niektóre ośrodki (np. Zermatt, Saas-Fee, Riederalp, Kühboden) tworzą strefy wolne od ruchu samochodowego i ograniczają liczbę miejsc na parkingach oraz przepustowość wyciągów.

Degradacja wód wynika głównie z faktu nadmiernego zużycia wody przez turystów (na statystycznego turystę przypada dziesięciokrotnie więcej wody niż na mieszkańca) oraz wskutek wielkiej ilości ścieków, trudnych w tych warunkach do oczyszczenia i odprowadzenia. Jest to szczególnie poważny problem na dużych wysokościach, gdzie podłoże nie ma zdolności filtracyjnych i ścieki spływają często wprost $w$ doliny. Zanieczyszczenie wody jest także skutkiem stosowania środków chemicznych używanych na trasach narciarskich. Niekorzystnym zjawiskiem w aspekcie ochrony wód jest wykorzystywanie lodowców jako terenów narciarskich, ponieważ zanieczyszczenia mogą być kumulowane wewnątrz lodowca, a po kilku latach mogą spowodować zanieczyszczenie wody pitnej. Należy dodać, że obszary górskie, w tym szczególnie Alpy, stanowią re- 
zerwuary wody pitnej (wieża ciśnień) dla dużej części Europy. Najwyższy poziom zanieczyszczenia obserwuje się w zimie, w okresie sezonu narciarskiego i równocześnie niskich stanów wód w potokach i rzekach alpejskich.

Szczególnie szkodliwe dla środowiska, w szczególności dla wód, gleb i roślinności jest używanie środków chemicznych. Na przykład stosowanie środków chemicznych dla przygotowania tras narciarskich na 36 obecnie wykorzystywanych lodowcach powoduje zanieczyszczenie wody pitnej związkami azotu i fosforu (Europe's Enwironment... 1995).

W ostatnich latach w licznych ośrodkach narciarskich w przypadku braku śniegu oraz w celu wydłużenia sezonu narciarskiego używa się maszyn do wytwarzania sztucznego śniegu. Zużywa się przy tym dużo energii i wody. Długo zalegający śnieg wpływa niekorzystnie na szatę roślinną, ograniczając krótki okres jej wegetacji i powodując często jej degradację. W 1992 r. 4 tys. armatek śnieżnych produkowało sztuczny śnieg, zużywając $28 \mathrm{mln}$ litrów wody na $1 \mathrm{~km}$ trasy narciarskiej (Europe's Enwironment... 1995).

Degradacja szaty roślinnej wskutek budowy infrastruktury jest zjawiskiem powszechnym. Na przykład przy budowie urządzeń na Zimową Olimpiadę w roku 1992 w Albertville wycięto 30 ha lasów.

W ostatnich jednak latach, dzięki postępowi w naukach biologicznych i postępowi technicznemu, możliwa jest rekonstrukcja naturalnej roślinności, dzięki czemu na zdegradowanych obszarach odtwarza się szybko porządaną roślinność. Poza tym odpowiednie przepisy prawne nakładają na przedsiębiorstwa budujące urządzenia turystyczne obowiązek rekultywacji obszarów zdegradowanych. Nie wywiązanie się z tego obowiązku grozi wysokimi karami, prowadzącymi do bankructwa projektowanych przedsięwzięć (B ät z i n g 1991).

Przykładem wielu negatywnych skutków ekologicznych i społeczno-ekonomicznych budowy stacji sportów zimowych może być francuska stacja Isola 2000. Zbudowana została na miejscu niewielkiej góralskiej wioski na wysokości ok. 2 tys. m n.p.m., gdzie zawsze w zimie występują dobre warunki śniegowe. Jest to typowa stacja narciarska z czterema hotelami i dużą liczbą apartamentów (łącznie ok. 1500 miejsc), z wielkim parkingiem na 550 samochodów oraz 22 wyciagami narciarskimi. Budowa wyciągów i tras narciarskich zmieniła zasadniczo naturalny krajobraz. Przy użyciu materiałów wybuchowych przez kilka lat modelowano teren, aby stworzyć najlepsze ukształtowanie tras i odpowiednie nachylenie stoków dla potrzeb narciarstwa. Stacja ta funkcjonuje tylko w sezonie zimowym, w lecie natomiast wszystko jest zamknięte. Zniknęła stara wioska góralska, po której pozostało kilka opuszczonych domów. Prawie wszyscy pracownicy stacji pochodzą z zewnątrz, niewielu mieszkańców znalazło tutaj zatrudnienie. Inwestycja sfinansowana została przez jeden bank. $Z$ dochodów ze stacji korzystają wyłącznie inwestorzy, region natomiast nie ma z niej żadnej korzyści (S t r a a t e n 1992). 
Podsumowując można stwierdzić, że negatywne dla środowiska przyrodniczego skutki masowej turystyki można znacznie ograniczyć, m. in. poprzez stosowanie optymalnych rozwiązań technicznych oraz rygorytsyczną i konsekwentną politykę ochrony środowiska. Innym rozwiązaniem jest propagowanie różnych form turystyki alternatywnej, w tym turystyki ekologicznej. Badania socjologiczne dowodzą jednak, że turyści mimo pełnej świadomości ekologicznej o szkodliwości dotychczasowych modeli turystyki, nadal preferują pobyt w ośrodkach zapewniających lepsze warunki wypoczynku niż formy będące w zgodzie z zasadami ochrony przyrody.

Jednym z elementów strategii „zrównoważonego rozwoju gór” może być koegzystencja rolnictwa i turystyki. Od rolnictwa bowiem może w dużym stopniu zależeć przyszłość Alp i innych ośrodków górskich. Zamieszkałe od wieków tereny Alp są przykładem harmonii pomiędzy przyrodą a gospodarką człowieka. Dlatego też rolnicy alpejscy odgrywają tu rolę strażników kulturowego krajobrazu i w interesie turystyki jest, aby nadal tu mieszkali i zajmowali się rolnictwem. Tak może być jedynie w przypadku, gdy turystyka będzie ich głównym źródłem dochodów, natomiast nie może nim być intensywne i zmechanizowane rolnictwo.

\section{PIŚMIENNICTWO}

A b e g g B., E 1 s a s s e r H., 1996, Klima, Wetter und Tourismus in den Schweizer Alpen, „Geographische Rundschau”, Bd. 48, H. 12.

B a r b i e r B., Herbin J., B illet J., B e vila cqua E., Jülg F., G räf P., $\mathrm{G}$ o $\mathrm{s}$ a $\mathrm{r}$ A., 1984, Le tourisme alpin, $25^{\mathrm{e}}$ Congres International de Géographie, Paris-Alpes.

B ät z i n g W., 1991, Die Alpen. Entstehung und Gefährdung einer europäischen Kulturlandschaft, München.

Europe's Environment. The Dobrišs Assessment, 1995, D. Stanners, Ph. Bourdeau (ed.), European Environment Agency, Copenhagen.

$\mathrm{K}$ u $\mathrm{r}$ e h a M., 1995, Wintersportgebiete in Österreich und Japan, „Innsbrucker Geographische Studien", H. 24.

$\mathrm{S} t \mathrm{r}$ a a $\mathrm{t}$ e $\mathrm{n}$ J., 1992, Appropriate Tourism in Mountain Areas, [w:] Tourism and the Environment. Regional, Economic and Policy Issues; ed. H. Briassoulis, J. van der Straaten, Dordrecht.

The transformation of Swiss Mountain Regions. Problems of development between self-reliance and dependency in an economic and ecological perspective, 1984, E. A. Brugger, G. Furrer, B. Messerli, P. Messerli (eds), Bern, Stuttgart.

Dr hab. Włodzimierz Kurek

Wpłynęło:

Instytut Geografii

22 grudnia $1998 \mathrm{r}$

Uniwersytet Jagielloński

ul. Grodzka 64

31-044 Kraków 


\section{RESUME}

Pendant plusieurs siècles les Alpes étaient exclusivement le terrain de l'économie agricole et de la sylviculture. Traditionnellement peu productive l'agriculture ne garantissait pas la subsistance à la population dont le nombre croissait toujours. La demande de la main-d'oeuvre bon marché, résultant de la révolution industrielle, a entraîné le reflux en masse de la population, ce qui dans certaines parties des Alpes a eu pour effet presque le dépeuplement des montagnes.

Seulement le développement du tourisme, avant tout après la ${ }^{\mathrm{I}} \mathrm{e}^{\mathrm{e}}$ guerre mondiale, a causé l'animation économique dans plusieurs régions alpestres. En même temps le développement intense du tourisme est devenu un facteur de la dégradation du milieu. Le skiage était la plus dynamique forme du tourisme. Hélas, pour exploiter les valeurs neigeuses, il fallait construire plusieurs installations techniques et établir l'infrastructure de couchage et des services. Par conséquent, la grande partie du terrain alpestre est coupée par le dense réseau des remonte-pentes pour les skieurs et des voies de ski, et sur les crêtes et les versants s'élèvent les centres de skiage. Leur construction a occasionnée la transformation irrévocable du milieu naturel et du paysage alpestre.

La plus intense période du développement du tourisme, celui hivernal surtout, commence après la II ${ }^{\mathrm{e}}$ guerre mondiale. Plusieurs localités visitées jusqu' alors seulement en été, grâce au développement des sports d'hiver, ont été transformées en centres des deux saisons.

Cependant le tourisme d'hiver se concentre principalement dans les grandes monofonctionnelles stations des sports d'hiver localisées au-dessus des colonies humaines. De tels centres se trouvent à présent surtout dans les Alpes Françaises et Italiennes. Ils garantissent l'exploitation de la neige pendant la longue saison d'hiver (ceux qui sont localisés sur les glaciers fonctionnent pendant toute l'année). Ils sont modernes et leur efficacité économique est plus grande que celle des centre traditionnels.

Le mouvement touristique dans les Alpes est énorme. Chaque année y arrivent 100000000 de touristes. $40 \%$ des nouveaux-venus y passent leurs vacances, $60 \%$ - leurs week-ends. Il est à rémarquer, que depuis 20 ans le nombre des touristes estivaux reste toujours le même, tandis que celui des touristes hivernaux s'augmente rapidement. Le nombre des touristes arrivés en 1990 dans les Alpes pour faire du ski est évalué à 50000000 . 600 centres des sports d'hiver et 14000 teleskis y fonctionnent à présent (Europe's Environnement... 1995).

Le tourisme de ski exerce une très grande et négative influence sur le milieu naturel des Alpes. La construction des itinéraires et de l'infrastructure différente, y compris les routes et les parkings a occasionné la destruction de grands terrains forestiers et a changé considérablement le paysage; elle a aussi augmenté la fréquentation des avalanches. Pour construire les stations des sports d'hiver, il fallait transformer de grandes superficies des pentes montagnardes à l'aide de matériaux explosifs et de puissantes machines. Les voitures dont le nombre s'augmente toujours polluent l'air. Pour maintenir la pureté de l'air et éliminer le vacarme certains centres (exemple: Zermatt, Saas Fee, Riederalp, Kühboden) créent des zones où l'entrée des voitures est interdite, limitent le nombre des lieux de parking et celui des utilisateurs des teleskis.

La dégradation des eaux résulte de l'utilisation excessive de l'eau et de la production des eaux usées, qu'il est difficile d'épurer et d'évacuer. Le problème est particulièrement grave aux grandes hauteurs, où le sol est impénétrable et les eaux usées coulent directement dans les vallées. L'utilisation des glaciers pour les terrains de skiage est un phénomène désavantageux, car les impurtés peuvent s'accumuler à l'intérieur du glacier et aprés quelques années polluer les eaux potables. Il est à savoir, que les terrains montagnards, particulièrement les Alpes, constituent le reservoir d'eau potable (château d'eau) pour la grande partie de l'Europe.

Dernièrement dans les nombreux centres de ski, lorsqu'il manque de neige pour allonger la saison de skiage, on use des machines pour produire la neige artificielle. Pour le faire il faut utiliser beaucoup d'eau et d'énergie. La neige qui reste trop longtemps sur le tapis végétal lui nuit en limitant la période de sa végétation ou bien le dégradant souvent.

En assumant, on peut constater, que les effets négatifs du tourisme en masse pour le milieu naturel pourraient être gravement limités par l'application des solutions techniques optimales et 
par la politique rigoureuse et conséquente de la protection du milieu. Une autre solution c'est la propagation des formes du tourisme alternatif, y compris du tourisme écologique. La coexistence de l'agriculture et du tourisme peut être un des éléments de la stratégie du développement équilibré des montagnes. L'avenir des Alpes et des autres terrains montagnards peut dépendre en grande mesure de l'agriculture. Les agriculteurs alpestres jouent le rôle des gardiens du paysage culturel et l'intérêt du tourisme exige qu'ils vivent là où ils vivent et labourent la terre.

Traduit par Lucjan Kowalski

\section{SUMMARY}

For many centuries the Alps were exclusively an area of agriculture and forestry.

Traditional, ineffective agriculture did not give any opportunities to support the fast growing population. Therefore a demand for cheap workforce resulting from the industrial revolution, caused massive outflow of population, which in some parts of the Alps led to almost complete depopulation of the mountains.

Only the development of tourism, especially after World War II, caused the economic awakening of many Alpine regions. At the same time, however, the development of tourism became a factor of the environmental degradation. The most dynamic form of tourism was skiing. In order to let people enjoy the snow, it is necessary, unfortunately, to build numerous technical facilities and a whole infrastructure of hotels and services. As a result a greater part of the Alps is at present cut with ski lifts and skiing routes, and on the high ridges and slopes there are buildings. Their appearance caused irreversible transformations in the natural environment and Alpine landscape.

The most intensive development of tourism, and especially winter tourism, occurred in the years following World War II. Many places used before only in the summer season, changed into two-season centres, due to the development of winter sports. Mostly, however, the winter tourism is nowadays concentrated in large, single-function stations of winter sports, located above permanent settlements. Such centres can be found even today in the French and Italian Alps. They ensure benefiting from the long winter season (some of them, located on glaciers, function throughout the year), they are modern and more effective economically than the traditional centres.

The tourist traffic in the Alps is estimated at 100 million tourist a year, $40 \%$ of which are holiday arrivals and $60 \%$ - weekend arrivals. It is significant that for over 20 years the number of tourists in the summer season have remained unchanged, while the number of tourists in the winter season has been growing fast. It is estimated that in 1990 about 50 million tourists came to the Alps in order to ski. There are about 600 winter sports centres and about 14 thousand ski lifts here. (Europe's Environment... 1995).

The ski tourism has a very strong and harmful influence on the natural environment of the Alps. Building the skiing routes and varied infrastructure, including roads and parking lots, caused the destruction of large forest areas, changed the landscape considerably, increased the frequency of avalanches. Building winter sports stations often requires transforming a large area of mountain slopes, which is done with explosives and powerful machinery. The result of a tremendous car traffic is air pollution. In order to protect the air and to eliminate the noise, some centres (e.g. Zermatt, Saas-Fee, Huhboden) create zones free of car traffic and limit the number of spaces at parking lots and the capacity of the ski lifts.

The degradation of waters results mainly from the excessive use of water by tourists, as well as from a large amount of sewage, which in the mountains is difficult to rectify and divert. It is a particularly serious problem at high altitudes, where the ground lacks filtering properties and the sewage often flows straight to the valley. A negative phenomenon as far as waters are concerned, 
is using the glaciers as skiing areas, because the refuse may be accumulated inside the glacier, and after a few years it may cause pollution of the drinking water. It should be added that mountainous regions, and the Alps in particular, are reservoirs of drinking water (a water-tower) for a large part of Europe.

In recent years in many skiing resorts, when there was not enough snow or in order to prolong the skiing season, machines have been used to produce artificial snow. A lot of energy and water is used. Snow which stays too long on the ground badly affects the plants, shortening the time of their vegetation, and often destroys them.

In conclusion, one can state that the negative effects of massive tourism for the natural environment could be considerably limited by, among other things, using optimum technical solutions and by strict and consistent policy of environmental protection. Another solution is to propagate different forms of alternative tourism, like the ecological tourism. One of the elements of the strategy of a balanced development of the mountains might be a co-existence of agriculture and tourism. The future of the Alps and other mountainous regions may depend on agriculture. Alpine farmers play the role of the guardians of the cultural landscape and it is in the interest of tourism for them to continue living and working there. 